\title{
Voluntary Counselling and Testing for HIV in the dental setting: Knowledge, attitudes and practices of oral health care workers in eThekwini district, KwaZulu-Natal
}

SADJ February 2021, Vol. 76 No. 1 p6 - p11

S Balwanth', S Singh ${ }^{2}$

\section{ABSTRACT}

\section{Introduction}

Oral health care workers are frequently at the forefront in recognizing oral manifestations of the Human Immunodeficiency Virus (HIV) and can therefore play a key role in screening and early detection of HIV in dental patients.

\section{Aim and objectives}

This study assessed oral health care workers' knowledge, attitudes and possible practices in Voluntary Counselling and rapid HIV testing (VCT) in the dental workplace in eThekwini district, KwaZulu-Natal so as to determine their understanding and support for these services.

\section{Methods}

This was a cross-sectional, descriptive study. A total of 120 questionnaires were distributed to oral health workers located in private and public dental settings in eThekwini district. One hundred $(n=100)$ completed questionnaires were retrieved, yielding a response rate of $83 \%$.

\section{Results}

The majority of participants (82\%) reported that HIV testing and counselling did not occur in their workplace. Participants $(87 \%)$ also indicated to have not been trained to perform HIV testing.

Sixty-six participants (66\%) reported willingness to implement HIV testing in their respective dental workplace. Less than half of the study population (41\%) were "unsure" regarding the accuracy of rapid HIV testing.

\footnotetext{
Author affiliations:

1. Sonam Balwanth: BChD (UWC), MMed (UKZN), PG Dip Int Ortho (UWC), Discipline of Dentistry: School of Health Sciences, University of KwaZulu-Natal, Durban, South Africa.

2. Shenuka Singh: $B O H, M S c$ (Dent), PhD, Postgrad Dip Health Res Ethics, Discipline of Dentistry: School of Health Sciences, University of KwaZulu-Natal, Durban, South Africa. ORCID Number: 0000-0003-4842-602X

Corresponding author: Shenuka Singh

Discipline of Dentistry, School of Health Sciences, University of KwaZulu-Natal, Durban, South Africa.

Private Bag X54001, Durban, 4000.

Email: singhshen@ukzn.ac.za

Author contributions:

1. Sonam Balwanth: Primary author - $70 \%$

2. Shenuka Singh: Secondary author $-30 \%$
}

\section{Conclusion}

Participants reported inadequate knowledge and practice of VCT. Participants had positive attitudes towards VCT implementation in the dental setting, provided that adequate training and support was available from the KwaZulu-Natal Department of Health.

\section{Keywords}

Rapid HIV testing, dental workplace, oral health care workers.

\section{INTRODUCTION}

Oral health care workers' knowledge, attitude and practices towards HIV testing and counselling, could reflect their understanding of the importance of early HIV screening in the dental workplace and in turn, play a role in contributing to improved management of the HIV crisis in KwaZulu-Natal. The prevalence of the Human immunodeficiency virus and Acquired immunodeficiency syndrome (HIV/AIDS) in South Africa, is high with $20.4 \%$ of the population being affected. ${ }^{1}$

Sadly, almost $18.23 \%$ of these affected populations are located in KwaZulu-Natal. ${ }^{2}$ HIV testing is considered an essential strategy in addressing the disease and provides an opportunity for oral health care workers to offer early HIV detection, and referral pathways as part of a comprehensive care package. ${ }^{3}$ The oral health care worker is at the forefront of recognizing oral manifestations of HIV, promoting rapid HIV testing, and curbing the detrimental effects of the disease through support and education. ${ }^{4}$

Likewise oral health care workers need to have adequate knowledge to understand the pathogenesis of HIV infections and recognize the associated symptoms so that proper diagnosis and clinical management can be implemented as part of comprehensive patient care. ${ }^{4,5}$ Additionally, patient education and counselling rely heavily on the oral health care worker's understanding of HIV. ${ }^{5}$

\section{VCT at the dental workplace}

Oral lesions are often clinical markers of HIV and can be used to predict the progression of HIV to AIDS. ${ }^{6,7}$ A South 
African study by Coogan et al. (2005) found that oral lesions may be present in up to $50 \%$ of HIV positive individuals and $80 \%$ of those with AIDS. ${ }^{6}$ The reported benefits of rapid HIV testing in the dental workplace, highlights a significant positive impact on patients visiting the dental sector. ${ }^{8,9,10}$ These reports reiterate the value and role of oral health care workers as an integral component in early HIV recognition and management. ${ }^{4,11,12}$

Studies examining oral health care workers' knowledge, attitudes, perceptions and practice regarding VCT at the dental workplace, suggested that oral health care workers were generally supportive of extending HIV testing services to the dental setting. However, the lack of HIV testing training for oral health care workers was seen as a common limiting factor for the implementation of such services. $^{4,13,14}$ Similarly, knowledge and skills related to VCT are pertinent to ensure proper testing and minimize possible false positive or false negative results. ${ }^{3,9}$

Despite the potential value of implementing HIV testing and counselling services within the dental setting, there is a paucity of published evidence in South Africa to examine this strategy. Rapid HIV testing has not yet been implemented to the dental workplace in KwaZulu-Natal, thereby creating an opportunity to explore this strategy further. To our knowledge, this is the first study conducted in KwaZulu-Natal to determine oral health care workers preparedness or willingness to engage in such service delivery.

\section{METHODS}

This was a cross-sectional, descriptive study that assessed oral health care workers' knowledge, attitudes and practices regarding VCT services as part of HIV management. The study sample was drawn from the private and public sectors in eThekwini district. The study sites included private dental practices $(n=60)$ and public health institutions $(n=8)$ in eThekwini district. Systematic sampling technique was used to select dental practices from a list obtained from Medpages.

Given that the majority of oral health care workers are located in the private sector in KwaZulu-Natal, two oral health care workers were identified from each site. A sample size of 100 oral health care workers was seen as adequate (at 95\% confidence level) to address the research question (personal communication with the statistician). A total of 120 questionnaires were distributed to the identified study sites and one hundred $(n=100)$ completed questionnaires were retrieved, yielding a response rate of $83 \%$.

The research instrument comprised a self-administered questionnaire which was validated by means of a pilot study which included $(n=5)$ oral health care workers from eThekwini to clarify any ambiguity in the questions posed. The questionnaire included 22 items. The first part of the questionnaire focused on information such as gender, age group, profession, place of work and work experience. The second part included questions pertaining to knowledge and practices with respect to HIV testing training, referral of patients with HIV associated oral lesions, commonly observed HIV oral manifestations, HIV testing at the dental workplace and knowledge of HIV testing. The third part of the questionnaire included questions related to oral health care workers' attitudes and perceptions of regarding HIV screening in the dental workplace.

A Likert 5-scale format of responses was used: 1-strongly agree, 2-agree, 3-not sure, 4-disagree and 5-strongly disagree to elicit respondents perceptions related to funding, resources, HIV testing, training and implementation of HIV testing in the dental workplace. The questionnaire consisted of closed ended and open-ended questions. Ethical clearance was obtained from the Biomedical Research Ethics Committee at the University of KwaZulu-Natal (BREC REF: BE400/17).

Participation was voluntary and written informed consent was obtained from all participants. The questionnaire was administered in English and isiZulu. Confidentiality and anonymity were maintained. Data was analyzed using SPSS version 24.0 (IBM Corp., USA). Univariate descriptive statistics, such as frequency and mean distribution were conducted for all variables.

The responses to the open-ended questions were grouped and emergent themes were examined and compared for possible associations. Inferential techniques included Pearsons chi squared test to assess a possible relationship between the independent variables (gender, age) and the dependent variables (perspectives on rapid HIV testing services in the dental workplace). A p-value $<0.05$ was considered to be statistically significant.

\section{RESULTS}

The total study population $(n=100)$ comprised dental surgeons (69\%), dental therapists (22\%), oral hygienists $(7 \%)$ and dental specialists (2\%). Study participants were located in private dental practices (57\%); public hospitals (34\%), public clinics (6\%) and mobile dental clinics (3\%) $(p<0.032)$. Participants $(31 \%)$ were predominantly within the age distribution of 41 >years old while $54 \%$ of the study sample were male (Table 1).

\section{Knowledge related HIV testing, rapid HIV testing, HIV training}

Almost all participants (99\%) indicated that HIV testing can be performed by obtaining the patient's blood sample $(\mathrm{p}<$ 0.001). However, $37 \%$ of participants indicated that HIV testing cannot be conducted using saliva samples from patients. Additionally, $30 \%$ of participants were "unsure" as to whether HIV can be tested using urine samples from patients, while $54 \%$ of participants reported to be "unsure" of other methods of HIV testing apart from the ELISA and Western Blot method.

While the majority of participants (89\%) reported to have heard of rapid HIV testing, 37\% of participants believed that the accuracy of rapid HIV testing was not same as the ELISA and Western Blot method and 41 participants were "unsure" (Table 2). The majority of participants (83\%) reported not to have received any training related to HIV counselling and testing. Almost all participants (94\%) supported the idea that oral health care workers should be trained in HIV counselling and testing at the undergraduate level. 
Positive attitudes and perceptions regarding voluntary counselling and testing for HIV in the dental workplace (Table 3)

The majority of participants $(87 \%)$ reported that opportunistic routine HIV testing services in the dental workplace was a good idea. Almost all participants (98\%) agreed that should HIV testing be offered to patients in the dental workplace, oral health care workers and staff should be adequately trained in VCT.

Participants (83\%) believed that opportunistic HIV testing in the dental workplace could contribute to increased awareness around HIV infections and reduce possible stigma and rejection associated with the disease.

Participants (83\%) also reported that HIV testing in the dental workplace was not a waste of medical resources and that such services could increase the possibility of patients seeking medical attention, which in turn could improve individual quality of life (93\%).

Two thirds of participants (66\%) reported willingness to implement HIV testing in their dental workplace while $80 \%$ believed that HIV testing is within the scope of dental practice. Additionally, the majority of participants (76\%) were comfortable treating a suspected HIV positive patient and $81 \%$ of the participants did not feel at risk for contracting the disease.

Some participants reported reasons for willingness to implement HIV testing to the dental workplace, which included: early detection and effective management of HIV $(n=13)$, awareness and knowledge of HIV status $(n=10)$ and decreasing occupational risk of undiagnosed HIV positive individuals $(n=3)$.

Sixty-seven participants (67\%) reported that an HIV testing policy is required in the dental workplace prior to the implementation of a testing strategy.

Negative attitudes and perceptions regarding Voluntary Counselling and Testing for HIV in the dental workplace

Overall, 34 participants (34\%) were not willing to implement HIV testing in their dental workplace, of which 26 participants were located in the private dental sector. Reported barriers or challenges in implementing HIV testing in the dental workplace $(n=34,34 \%)$ included: lack of suitability of HIV testing in the private practice due to time constraints and untrained staff $(26.5 \%)$, the sensitive nature of HIV (5.9\%), fear of stigmatization by patients (2.9\%), no official HIV testing policy for the dental workplace (2.9\%), and rapid HIV testing in the dental workplace was an additional stress (2.9\%).

Overall, the majority of participants (83\%) in this study indicated to not having sufficient staff to perform rapid HIV testing as well as pre-and post-testing counselling skills related to HIV testing. Participants that were not willing to undergo further training (18\%) provided reasons such as "nearing retirement" $(n=2)$, "not necessary in private practice" $(n=2)$, "not interested in the training" $(n=1)$ and "not a priority at the moment" $(n=1)$.
Clinical practice related HIV identification, testing and patient referral

More than two thirds of participants (68\%) indicated having a clinical workload of less than 5 patients per month that presented with possible HIV associated oral lesions. Some of the reported oral manifestations of HIV infections seen in patients presenting for dental management included oral candidiasis (63.3\%), necrotizing ulcerative periodontitis (57.1\%) and necrotizing ulcerative gingivitis (51\%).

Eighty-two participants (82\%) indicated that they did not conduct tests for HIV in patients presenting at their surgery/clinic. Almost all participants (98\%) reported to have referred patients with suspected HIV related oral lesions for further confirmatory tests.

\section{DISCUSSION}

While the majority of participants (89\%) reported to have heard of rapid HIV testing, only $18 \%$ indicated to have conducted rapid HIV testing in their dental setting. This finding is similar to that reported by Gumede in 2017, where the majority of participants in that study had heard of rapid HIV testing, yet only a few reported to have used rapid HIV testing. ${ }^{15}$ In the present study, almost all participants (82\%) supported the need for training opportunities in HIV counselling and testing.

This finding is consistent with Ramphoma and Naidoo, who also reported that very few dentists in their study had comprehensive knowledge of oral HIV lesions and that almost all participants expressed the need for further knowledge and training in this regard. ${ }^{16}$ The majority of participants $(68 \%)$ reported having a clinical workload of less than 5 patients per month that presented to their dental workplace with possible HIV associated oral lesions. Bhayat, Yengopal and Rudolph further add that oral lesions are useful clinical markers of HIV, but cautioned that the ability to recognize and diagnose these lesions are limited by the oral health care worker's skill and knowledge. ${ }^{11}$

The uncertainty reported by more than half of the participants (54\%) in this study with regards to the availability of other methods of HIV testing (apart from the ELISA and Western Blot method), could be an indicator of lack of continual holistic HIV education and information. Similarly, an investigation into HIV knowledge among undergraduate dental students in South Africa, showed acceptable knowledge in the spread of the disease, but poor understanding of HIV progression and oral manifestations of the disease. ${ }^{5}$

Almost $37 \%$ of participants in this study believed that the rapid HIV testing method was not as accurate as the ELISA and Western Blot methods. In contrast, a study by Moodley et al. demonstrated that the reliability of the HIV rapid tests could be compared with their corresponding ELISA results. ${ }^{17}$ Moodley et al. and Siegel et al. further postulated that the reliability of the rapid HIV tests is of a high caliber and that these tests are aligned with the standards set by the World Health Organization $(\mathrm{WHO}) \cdot{ }^{17,18}$ 


\begin{tabular}{|c|c|c|c|c|c|c|c|}
\hline \multirow{2}{*}{\multicolumn{2}{|c|}{ Biographical data }} & \multirow[t]{2}{*}{$\begin{array}{l}\text { Number of } \\
\text { participants }\end{array}$} & \multicolumn{4}{|c|}{$\begin{array}{c}\text { Would you implement HIV testing in } \\
\text { your dental workplace? }\end{array}$} & \multirow[t]{2}{*}{ P-value } \\
\hline & & & \multicolumn{2}{|c|}{ Yes } & \multicolumn{2}{|c|}{ No } & \\
\hline \multirow{2}{*}{ Gender } & Male & 54 & 32 & $(59.3 \%)$ & 22 & $(40.7)$ & \multirow{2}{*}{0.142} \\
\hline & Female & 46 & 34 & (73.9\%) & 12 & $(26.1 \%)$ & \\
\hline \multirow{4}{*}{ Age group } & 23-28 years & 24 & 17 & $(70.8 \%)$ & 7 & $(29.2 \%)$ & \multirow{4}{*}{0.965} \\
\hline & 29-34 years & 27 & 17 & $(63.0 \%)$ & 10 & $(37.0 \%)$ & \\
\hline & $35-40$ years & 18 & 12 & $(66.7 \%)$ & 6 & $(33.3 \%)$ & \\
\hline & $41>$ years & 31 & 20 & $(64.5 \%)$ & 11 & $(35.5 \%)$ & \\
\hline \multirow{4}{*}{ Profession } & Dental therapist & 22 & 18 & $(81.8 \%)$ & 4 & $(18.2 \%)$ & \multirow{4}{*}{0.053} \\
\hline & Dental surgeon & 69 & 43 & $(62.3 \%)$ & 26 & $(37.7 \%)$ & \\
\hline & Oral hygienist & 7 & 5 & $(71.4 \%)$ & 2 & $(28.6 \%)$ & \\
\hline & Dental specialist & 2 & 0 & $(0.0 \%)$ & 2 & $(100.0 \%)$ & \\
\hline \multirow{4}{*}{ Place of work } & Private Dental practice & 57 & 31 & $(54.4 \%)$ & 26 & $(45.6 \%)$ & \multirow{4}{*}{0.032} \\
\hline & Dental department in public hospital & 34 & 27 & $(79.4 \%)$ & 7 & $(20.6 \%)$ & \\
\hline & Dental department in public clinic & 6 & 5 & $(83.3 \%)$ & 1 & $(16.7 \%)$ & \\
\hline & Other (Mobile clinics) & 3 & 3 & $(100.0 \%)$ & 0 & $(0.0 \%)$ & \\
\hline \multirow{4}{*}{$\begin{array}{c}\text { Years of } \\
\text { experience }\end{array}$} & $1-5$ years & 28 & 20 & $(71.4 \%)$ & 8 & $(28.6 \%)$ & \multirow{4}{*}{0.363} \\
\hline & $6-10$ years & 24 & 13 & $(54.2 \%)$ & 11 & $(45.8 \%)$ & \\
\hline & $11-15$ years & 15 & 12 & $(80.0 \%)$ & 3 & $(20.0 \%)$ & \\
\hline & $>15$ years & 33 & 21 & $(63.6 \%)$ & 12 & $(36.4 \%)$ & \\
\hline \multirow{4}{*}{$\begin{array}{l}\text { Number of } \\
\text { patients seen on } \\
\text { weekly basis }\end{array}$} & $<50$ & 38 & 24 & $(63.2 \%)$ & 14 & $(36.8 \%)$ & \multirow{4}{*}{0.516} \\
\hline & $50-100$ & 41 & 26 & $(63.4 \%)$ & 15 & (36.6\%) & \\
\hline & $101-150$ & 12 & 8 & (66.7\%) & 4 & (33.3\%) & \\
\hline & $>150$ & 9 & 8 & (88.9\%) & 1 & (11.1\%) & \\
\hline
\end{tabular}

\begin{tabular}{|c|c|c|c|c|c|}
\hline \multirow[t]{2}{*}{ Questions } & \multirow[t]{2}{*}{ Total participants } & \multicolumn{3}{|c|}{ Knowledge } & \multirow[t]{2}{*}{ P-value } \\
\hline & & Yes & No & Unsure & \\
\hline Cheaper than the conventional testing? & 100 & $81.0 \%$ & $9.0 \%$ & $10.0 \%$ & 0.000 \\
\hline Quicker than the conventional testing? & 100 & $92.0 \%$ & $3.0 \%$ & $5.0 \%$ & 0.000 \\
\hline Less invasive? & 100 & $74.0 \%$ & $12.0 \%$ & $14.0 \%$ & 0.000 \\
\hline Useful in areas with minimal infrastructure? & 100 & $84.0 \%$ & $7.0 \%$ & $9.0 \%$ & 0.000 \\
\hline As accurate as ELISA and Western blot? & 100 & $22.0 \%$ & $37.0 \%$ & $41.0 \%$ & 0.000 \\
\hline
\end{tabular}

\begin{tabular}{|c|c|c|}
\hline $\begin{array}{l}\text { Early detection and effective } \\
\text { management of HIV } \\
\qquad(n=13 ; 28.9 \%)\end{array}$ & $\begin{array}{l}\text { Awareness and knowledge } \\
\text { of HIV status } \\
(n=10 ; 24.4 \%)\end{array}$ & $\begin{array}{l}\text { Decreasing occupational risk } \\
\qquad(\mathrm{n}=3 ; 7 \%)\end{array}$ \\
\hline \multirow{2}{*}{$\begin{array}{l}\text { 1. Early diagnosis could assist with improving } \\
\text { HIV/AIDS awareness. HIV testing offered at } \\
\text { the dental workplace could increase access } \\
\text { to communities that may not be seen time- } \\
\text { ously by medical staff due to busy clinics } \\
\text { and limited resources. }\end{array}$} & $\begin{array}{l}\text { 1. Routine HIV testing should be as important } \\
\text { as checking for blood pressure and blood } \\
\text { glucose levels. }\end{array}$ & \multirow{2}{*}{$\begin{array}{l}\text { 1. Due to exposure to potential contaminations } \\
\text { and high number of HIV positive patients, } \\
\text { testing is prudent as staff are always aware } \\
\text { of risk, even with the use of personal protec- } \\
\text { tive equipment. }\end{array}$} \\
\hline & $\begin{array}{l}\text { 2. A large number of patients access dental } \\
\text { services only and many of them do not know } \\
\text { their status, so knowledge is key. }\end{array}$ & \\
\hline $\begin{array}{l}\text { 2. HIV testing in the dental workplace is use- } \\
\text { ful for the patient's welfare. The broadest } \\
\text { spectrum of facilities should offer testing. }\end{array}$ & $\begin{array}{l}\text { 3. Any means to increase awareness and HIV } \\
\text { testing is good. Dentists can also be expos- } \\
\text { ed to blood, so knowing a patient's status } \\
\text { is important. }\end{array}$ & $\begin{array}{l}\text { 2. There are times where oral health care work- } \\
\text { ers do get injuries and are so busy at work } \\
\text { that they neglect to test themselves. There- } \\
\text { fore HIV testing at the dental workplace is } \\
\text { vital. }\end{array}$ \\
\hline $\begin{array}{l}\text { 3. Patients can be counselled at the earliest } \\
\text { and treatment can commence promptly. }\end{array}$ & \multirow{2}{*}{$\begin{array}{l}\text { 4. HIV is a major problem. Patients can get } \\
\text { tested quicker and know their status, there- } \\
\text { by reducing the negative impact on the } \\
\text { country. }\end{array}$} & \multirow[t]{2}{*}{$\begin{array}{l}\text { 3. HIV testing at the dental workplace is inte- } \\
\text { gral, as we, health care workers, are always } \\
\text { at risk of contracting HIV/AIDS. }\end{array}$} \\
\hline $\begin{array}{l}\text { 4. Patients will know their status and how to } \\
\text { look after themselves better. }\end{array}$ & & \\
\hline
\end{tabular}

Thus rapid HIV tests could be a quick and cost effective method of testing for HIV. ${ }^{17,18}$ The authors however also highlighted the need for ongoing training, monitoring, and review of rapid HIV testing methods. 17,18,19

According to $\mathrm{WHO}$, "scaling up VCT is a public health and human rights imperative and must be linked to extensive efforts to achieve universal access to comprehensive HIV prevention, treatment, care and support". 20:p.4 In line with WHO's recommendation, the South African
Department of Health outlined requirements for providerinitiated counselling and testing (PICT) services in all healthcare facilities. ${ }^{21}$ This could also be extended to the dental workplace.

This is further supported by Bassett et al. who reported that routine voluntary HIV testing was able to identify nearly five times as many new cases per week. ${ }^{22}$ Hence, early diagnosis of HIV is essential for the improvement of treatment outcomes. ${ }^{23}$ Vulnerable groups including chil- 
dren should not be excluded in the HIV screening and testing strategies. According to Mohamed et al., a high prevalence of dental caries $(78.8 \%)$ and an unmet treatment need of $90.4 \%$ were recorded among children with HIV/AIDS that visited the dental clinic in the Western Cape. ${ }^{24}$ This again highlights the role that oral health care workers can play in HIV detection. Therefore, health planning in the district should include opportunities for oral health care to be integrated into HIV education and clinical management such as early diagnosis of HIV. ${ }^{4}$ These initiatives could contribute to strengthening the health system's response to HIV infections in the district and in the province.

The majority of participants (66\%) indicated willingness to implement HIV counselling and testing in their dental workplace. This study finding is consistent with many international studies. ${ }^{13,25,26,27}$ An Australian study showed that the majority of dentists surveyed, supported rapid HIV testing in the dental workplace, with a large number of dentists advocating for immediate availability of rapid HIV testing. ${ }^{25}$

Similarly, a study by Abe, Kolude and Adeyemi, suggested that Nigerian dentists acknowledged the dental workplace as being an extended platform for HIV testing and were optimistic about incorporating HIV testing into the dental setting, as well as expressed their willingness to undergo training for HIV testing. ${ }^{13}$ Pollack et al. found that dentists supported the importance of annual HIV testing for high risk individuals and expressed willingness to perform screening and testing for HIV. ${ }^{26}$ Hutchinson et al. reported that rapid HIV testing was advocated when this service was within the scope of the dental practitioners' training. ${ }^{27}$

The present study indicated that the majority of participants $(76 \%)$ were comfortable treating a suspected HIV positive patient and $81 \%$ of the participants did not feel at risk for contracting the disease. Conversely, an Indian study found that only $60.7 \%$ of dentist participants were willing to treat HIV positive patients and $70.4 \%$ of the participants reported to be placed at an increased personal risk when treating suspected HIV positive patients. ${ }^{28}$

One possible reason for this reported difference could be the inherent practitioner attitudes and beliefs around HIV. Additionally, strategies such as the National Strategic Plan 2017-2022 and UNAIDS 90-90-90 could play a role in increasing practitioner and public awareness of HIV. 29,30 More research is required in this area to fully understand how practitioner beliefs and attitudes could influence their perceptions of risks related to HIV.

While the majority of participants in this study recognized the benefits of opportunistic HIV testing in the dental workplace, some barriers were also reported. These included: lack of appropriate training and skills in HIV counselling and testing and no clear guidelines on remuneration and support from the KwaZulu-Natal Department of Health. These findings are similar to other studies that reported oral health care workers from the private dental sector were less likely to implement HIV testing in the dental workplace due to lack of counselling skills, resources, time constraints and perceptions that these services were not relevant within the scope of dentistry. ${ }^{31,32}$ A study by Siegel et al. suggested that dental practitioners were less likely to implement HIV testing in the dental setting due to the following reasons: liability for incorrect results, offending or upsetting patients, HIV testing as a procedure not within the dental scope, low acceptance of HIV testing in dental workplace, potential negative impact on the private dental practice, inadequate reimbursement, cost and time. ${ }^{18}$ Abe et al. added that lack of interest in HIV testing in the dental workplace was possibly linked to poor understanding of rationale behind rapid HIV testing, lack of insurance coverage (medical aid), and further cautioned that policy statements should come from governing authorities and not oral health care workers. ${ }^{13}$

Overall, this study indicated that oral health care workers' knowledge and training regarding HIV testing were inadequate. There was very little evidence to suggest that oral health workers actually provided HIV testing in the dental workplace. However, oral health care workers' attitudes and perceptions towards implementing HIV testing to the dental workplace was one of optimism and willingness. A suggestion to improve HIV testing in dental settings in eThekwini district could include the development an oral health HIV testing policy to guide such services in both the public and private dental sectors. However such policy development should involve all stakeholders to ensure inclusiveness in decision making and practitioner buy-in.

Oral health policy and planning in the district and province could glean from best practices in HIV counselling and testing services in other countries and adapt these to local settings. ${ }^{8}$ From an educational perspective, training on HIV testing and counselling could be incorporated into the undergraduate dental curricula so as to better prepare dental graduates. Similarly refresher courses on voluntary HIV testing and counseling could be offered as part of continuing professional development for practitioners. In this way, patients could have increased accessibility to HIV testing and counselling with appropriate referral pathways for management and care. Simultaneously, oral health care workers could play more meaningful roles in addressing the HIV pandemic.

\section{Study limitations}

The study provided valuable insight into oral health care workers' knowledge, attitudes and practice of HIV testing, but some limitations were noted. The study focused exclusively on oral health care workers in the eThekwini district thus the generalizability of the study findings are limited. More research is required on a larger scale (national level) to further explore oral health care workers' knowledge, attitudes, perceptions towards HIV testing and counselling. It would be important to understand the interplay between oral health care workers' HIV knowledge and training and social and cultural norms that influence oral health care workers' attitudes and perceptions towards HIV testing. Over-reporting could have also been present with regards to oral health care workers' HIV testing practices. This observation is consistent with findings by Singh and Pottapinjara, and Ahamed et al. who also suggested that self-reported data could be over or under-reported in an effort to conform to social desirability. 33,34 


\section{CONCLUSION}

The results indicated that oral health care workers' HIV testing knowledge and practice of HIV testing is suboptimal. The majority of participants indicated not having training or skills in pre- and post-test HIV counselling and testing, but were generally optimistic towards offering HIV testing and counselling in the dental workplace. More guidance and direction are required from the KwaZulu-Natal Department of Health to operationalize such services.

\section{Acknowledgement}

Dr NR Maharaj, (Department of Health) for his guidance and input.

\section{References}

1. UNAIDS. HIV and AIDS in South Africa. Avert Organization. 2019 [cited 16 September 2020]. Available from: https://www. avert.org/professionals/hiv-around-world/sub-saharan-africa/ south-africa.

2. Low M, MacDonell S. Graphs that tell the story of HIV in South Africa's provinces. Spotlight. 2019 [cited 16 September 2020]. Available from: https://www.spotlightnsp.co.za/2019/08/05/ graphs-that-tell-the-story-of-hiv-in-south-africas-provinces/.

3. National Department of Health of South Africa. National HIV Testing Services Policy: 2016. 2015; 23.

4. Campo J, Cano J, del Romero J, et al. Role of the dental surgeon in the early detection of adults with underlying HIV infection/AIDS. Med Oral Patol Oral Cir Bucal. 2012; 17(3).

5. Galane M. Knowledge, attitude and practices regarding HIV/ AIDS among dental students at Medunsa oral health centre. University of Limpopo; 2012.

6. Coogan MM, Greenspan J, Challacombe SJ. Oral lesions in infection with human immunodeficiency virus. World Health Organization Bulletin. 2005; 83(9): $700-6$.

7. Berberi A, Aoun G. Oral lesions associated with human immunodeficiency virus in 75 adult patients: a clinical study. Journal of the Korean Association Oral Maxillofacial Surgeons. 2017; 43(6): 388.

8. Bradley ELP, Vidot DC, Gaul Z, Sutton MY, Pereyra M. Acceptability of oral rapid HIV testing at dental clinics in communities with high HIV prevalence in South Florida. PLoS One. 2018. Available from: https://doi.org/10.1371/journal.pone.0196323.

9. Austin C. Rapid HIV Testing in the Dental Office. DentistryiQ. 2009. Available from: http://cdeworld.com/courses/20185-Rapid_HIV_Testing_in_the_Dental_Office.

10. Santella A, Conway DI, Watt RG. The potential role of dentists in HIV screening. British Dental Journal. 2016; 220(5): 229-33.

11. Bhayat A, Yengopal V, Rudolph M. Predictive value of group I oral lesions for HIV infection. Oral Surgery, Oral Medicine, Oral Pathology, Oral Radiology and Endodontology. 2010; 109(5): 720-3.

12. Agbelusi GA, Eweka OM, Umeizudike KA, Okoh M. Oral manifestations of HIV. IntechOpen. 2013. doi: 10.5772/52941.

13. Abe E, Kolude B, Adeyemi B. HIV testing in dental practice: perception and attitude of dentists in Southwestern Nigeria. African Journal of Medicine and Medicinal Science. 2014; 43(1): 201-8.

14. Parish CL, Siegel K, Liguori T et al. HIV testing in the dental setting: perspectives and practices of experienced dental professionals. AIDS Care. 2017; 30(3): 347-52.

15. Gumede S. Knowledge, Attitudes and Perceptions of Health Care Users Towards HIV Self-Testing At Selected Gateway Clinics At eThekwini District, Kwazulu-Natal. AIDS Research and Treatment. 2017; 15(1):103-9.
16. Ramphoma KJ, Naidoo S. Knowledge, attitudes and practices of oral health care workers in Lesotho regarding the management of patients with oral manifestations of HIV/AIDS. SADJ. 2014; 69(10):446,448-53.

17. Moodley D, Moodley P, Ndabandaba T, Esterhuizen T. Reliability of HIV rapid tests is user dependent. South African Medical Journal. 2008; 98(9): 707-11.

18. Siegel K, Abel SN, Pereyra M, et al. Rapid HIV testing in dental practices. Am J Public Health. 2012; 102(4): 625-32.

19. Mwisongo A, Peltzer K, Mohlabane N, Tutshana B. The quality of rapid HIV testing in South Africa: An assessment of testers' compliance. African Health Sciences. 2016; 16 (3): 646-54.

20. WHO. Scaling up HIV testing and counselling in the WHO European Region as an essential component of efforts to achieve universal access to HIV prevention, treatment, care and support policy framework. 2010: 4.

21. Hansoti B, Hill SE, Whalen M, et al.. Patient and provider attitudes to emergency department-based HIV counselling and testing in South Africa. South African Journal of HIV medicine. 2017; 18(1).

22. Bassett IV, Giddy J, Nkera J, et al. Routine Voluntary HIV Testing in Durban, South Africa: The experience from an outpatient department. Journal of acquired immune deficiency syndromes. 2007; 46(2): 181-6.

23. Dimba EAO, Yengopal V, Joshua E, Thavarajah R, Balasundaram S. Access and management of HIV-related diseases in resource-constrained settings: a workshop report. Oral Diseases. Wiley Online Library. 2016; 22 (S1):206-210.

24. Mohamed N, Mathiba OP, Mulder R. Oral status of HIV-infected children aged 12 years or younger who attended a Paediatric Infectious Diseases Clinic in Cape Town. Clinical and Experimental Dental Research. 2019; 6(1): 75-81.

25. Santella AJ, Schlub TE, Schifter M, Tolani M, Hillman RJ. Australian dentists' perspectives on rapid HIV testing. Australian Dental Journal. 2015; 61(3).

26. Pollack HA, Pereyra M, Parish CL, et al. Dentists' Willingness to Provide Expanded HIV Screening in Oral Health Care Settings: Results From a Nationally Representative Survey. American Journal of Public Health. 2014; 104(5): 872-80.

27. Hutchinson MK, van Devanter N, Phelan J, et al. Feasibility of implementing rapid oral fluid HIV testing in an urban University Dental Clinic: a qualitative study. BMC Oral Health. 2012; 12(1).

28. Dhanya RS, Hegde V, Anila S, et al. Knowledge, Attitude, and Practice towards HIV Patients among Dentists. J Int Soc Prev Community Dent. 2017; 7(2):148-53.

29. South African National Aids Council (SANAC). The National Strategic Plan (NSP) 2017- 2022. 2016.

30. [cited 22 September 2020]. Available from: http://nsp.sanac. org.za/.

31. UNAIDS. Ending Aids: Progress Towards the 90-90-90 Targets. Joint United Nations Programme on HIV/AIDS. 2017. [cited 22 September 2022] Available from: https://www.unaids.org/ en/resources/documents/2017/20170720_Global_AIDS_update_2017.

32. Patton L, Santos V, McKaig R, Shugars D. Education in HIV risk screening, counseling, testing, and referral: survey of U.S. dental schools. Journal of Dental Education. 2002; 66(10): 1169-77.

33. Greenberg BL, Glick M, Julie FH, Kantor ML. Dentists' attitudes toward chairside screening for medical conditions. Journal of the American Dental Association. 2010; 141: 52-62.

34. Singh S, Pottapinjara S. Dental undergraduate students' knowledge, attitudes and practices in oral health self-care: A survey from a South African university. African Journal of Health Professional Education. 2017; 9(2): 83-7.

35. Ahamed S, Moyin S, Punathil S, et al. Evaluation of the oral health knowledge, attitude and behavior of the preclinical and clinical dental students. Journal of International Oral Health. 2015; 7(6): 65-70. 